\title{
Mentoring online graduate students: partners in scholarship
}

\author{
SHERRI MELROSE
}

Keywords: e-learning, international, mentoring, nursing, postgraduate education

\section{SUMMARY}

Mentoring graduate students toward scholarly research and writing activities has become an important area of focus for faculty at the Centre for Nursing and Health Studies at Athabasca University in Alberta, Canada. With an emphasis on teaching excellence, instructors seek out and create experiences to involve graduate students in their own programme of research and publication. However, despite a plethora of literature available on the concept of mentoring, few definitive guidelines exist to illustrate what the process might look like within Masters programmes offered exclusively through a WebCT online environment. This paper describes an approach to mentoring two graduate students in the Master of Health Studies programme that was perceived as positive and mutually beneficial for the protégés as well as the mentor. Insights are revealed into the experiences that these students found both engaging and difficult as they developed skills in analysing qualitative research and submitting manuscripts for publication. The students' stories are discussed to describe significant features of the experience of

\section{WHAT IS ALREADY KNOWN IN THIS AREA}

Considerable research from a variety of disciplines is available on the value of mentoring - both in long-term relationships as well as for only short periods of time. Traditionally, faculty/student collaboration on publications has been limited.

\section{WHAT THIS WORK ADDS}

An illustration of what the process can look like in a graduate programme offered exclusively through a WebCT online environment. Case studies highlight experiences that engaged students and those that were difficult.

\section{SUGGESTIONS FOR FUTURE RESEARCH}

How can primary care educators intentionally create mentoring opportunities that extend their own scholarly activities to include student protégés? 
'partnering in scholarship' with their teacher. Suggestions and practical strategies for mentoring online graduate students are offered.

\section{INTRODUCTION}

'In the Greek mythology tale The Odyssey, when King Odysseus left home for the Trojan Wars, he asked his trusted friend Mentor to care for his wife and infant son Telemachus. During the 20 years Odysseus was away, Mentor not only educated Telemachus, but was also responsible for shaping his character, counseling him to make wise decisions and advising him to remain clear and steadfast. Since then, wise and trusted advisers have been called "mentors".,

This article describes the experience of mentoring, or seeking to offer 'wise and trusted' guidance to two online graduate students in the Master of Health Studies (MHST) programme at the Centre for Nursing and Health Studies, Athabasca University, Athabasca, Alberta, Canada as they developed skills in analysing qualitative research and submitting manuscripts for publication.

The MHST programme is completed exclusively online using a WebCT course management system. The primary medium for communication, instruction and assessment within the programme is asynchronous text-based threaded discussions within a WebCT environment. In keeping with an intentional commitment to support mentoring connections, instructors are invited to involve learners in their own scholarly activities. Examples of one-onone opportunities to mentor students include extending an aspect of a course and employing students as research assistants. This paper illustrates how extending an aspect of a course (in this case an assignment) into co-authoring a manuscript and employing a student as a paid research assistant both created meaningful mentoring opportunities.

\section{LITERATURE REVIEW}

A literature review revealed that considerable research has been undertaken to investigate the value and benefits of mentoring for both mentors and their protégés within healthcare learning events. There is a 'gap', however, in our understanding of how graduate study faculty can provide mentorship to learners in an exclusively online learning environment. In particular, specific direction for involving students in scholarly activities, such as faculty research projects and publication efforts, is lacking.

Traditionally, and well before online learning opportunities became available, publications extending from faculty-student research collaboration have also been limited. Taylor studied 285 nurses in academia who stated that, while they felt that they had been mentored, they had not collaborated in research $(56 \%)$, co-authored a paper $(71.2 \%)$ or presented a paper with a mentor $(74.7 \%))^{2}$ Similarly, Whitley and Oddi explored the influence of selected factors on the publishing efforts of student authors who published in the Western Journal of Nursing Research during a fiveyear period, and identified that, although faculty were involved as research advisors for a majority of students and spent several hours per week in supervising students' research activities, the existence of collaborative mentorship culminating in student faculty co-authorship was not apparent. ${ }^{3}$ Further, after an exploration of factors that influenced student authors who published in Nursing Research during a five-year period, Whitley and colleagues called for graduate study educators to examine mentoring in more depth, and to encourage collaboration in authorship with students. ${ }^{4}$

Anecdotal reports of the benefits of the mentoring relationship, especially for women, are well documented. Byrne and 
Keefe noted that, even when resources were limited and optimal long-term relationships with expert research mentors were not available, women valued inclusion in projects over short periods and multiple sources of mentors across their careers. ${ }^{5}$ Faculty researchers who mentor well can increase their own productivity in addition to strengthening their school's reputation and resources. ${ }^{6}$ Braithwaite described the excitement of the mentoring relationship while conducting collaborative international research. ${ }^{7}$ Owens and Patton used examples of an email mentoring experience to illustrate a win-win situation for both participants. ${ }^{8}$

Barriers to mentoring are also acknowledged. These can include limited time to offer additional instruction and a lack of confidence. ${ }^{9}$ And, when the mentor is also the teacher, there may be conflicts between mentoring and other teaching roles, such as evaluation and discipline. ${ }^{10}$ Role confusion may develop as teachers take on a mentoring role. Teachers are often advised to keep a professional distance when interacting with students and this can conflict with the belief that a mentor should be a friend and confidant. ${ }^{11}$ Further, in relation to the imbalance of power, teachers may be concerned that their own self-serving need to 'publish or perish' may influence the relationship and constitute exploitation of students. ${ }^{3}$

Additionally, suggestions for implementing processes that contribute to successful mentoring have been identified. At the beginning of a project, MorrisonBeedy and colleagues noted that the key factors for effective implementation of research mentoring are to set clear goals for the project, define expectations for the protégés, establish and maintain good communication and share values related to research. ${ }^{12}$ During the selection of protégés, Paul and colleagues asserted that enthusiasm, willingness to participate and having the time available to commit to the project are more important than grade point averages. ${ }^{6}$
In setting up collaborative writing plans, Davidhizar and Dowd stressed the importance of determining the sequence in which authors will be listed on any manuscripts. ${ }^{13}$ Correspondingly, Klein and Moser-Veillon affirmed the need to articulate that substantive contributions are expected to claim a byline. ${ }^{14}$

As the relationship progresses, Brey and Ogletree advised striking a balance between personal and professional issues and investing in time and patience. ${ }^{15}$ Also, Thorpe and Kalischuk indicated that performing collaborative formative and summative evaluations are helpful. ${ }^{16}$ Furthermore, given the goal of independent functioning for the protégé, and the intense and frequent contact within the relationship, Owens and Patton pointed out the importance of attending to closure. ${ }^{8}$

However, while a body of research related to the processes involved in mentoring healthcare learners towards scholarly research and writing activities continues to evolve, illustrations of what the experience might look like in an online environment are limited. Next, to offer examples of practical teaching strategies that respond to experiences which students found engaging as well as difficult, I describe my own experience of partnering in scholarship with two online students, Terry and Cate.

\section{THE MENTORING APPROACH}

The mentoring approach used with Terry and Cate was guided by a constructivist student-centred conceptual epistemology and framed from the Daloz mentorship model. ${ }^{17,18}$ Daloz presented a mentorship model for the teaching of adults which was drawn from mythic figures such as Mentor in The Odyssey and which used the metaphor of learners undergoing a developmental journey. Effective mentors, he suggested, can encourage and partner with protégés at different times in their learning journeys by offering support, challenge 
and vision. In the area of support, Daloz emphasised a commitment to nurture the relationship and to create a climate of trust in which the protégé feels safe to risk taking on new perspectives and make mistakes. In the area of challenge, Daloz proposed the idea of introducing tension by raising disorienting questions or setting tasks. In addition, in the area of vision, Daloz recommended providing a sense of direction and movement towards where the journey leads. ${ }^{18}$

\section{THE PROTÉGÉS}

\section{Terry's story}

Terry is a Registered Dietitian who I worked with on two online courses. She consistently participated in online discussions, sought help when she needed it and didn't hesitate to express her opinions. In fact, with one of her class papers, in addition to presenting a well-organised and comprehensively referenced assignment, Terry described an incident that caused me to laugh out loud. I agreed with Terry's description of the incident and found her suggestions for change intriguing. However, in my feedback, I did encourage her to frame her academic comments with less flamboyance.

Terry was employed on a contract basis with three different employers, travelled widely, and, like most online students at the Centre, completed one graduate course each fall, winter and spring term. Although her time was clearly stretched, Terry hoped to obtain a full-time teaching position and viewed writing for publication as an important personal learning objective. As a supplemental work project, I offer a standing invitation to all members of my classes to collaborate with me and develop one of their course assignments into a manuscript that might be disseminated at a conference or in an academic journal. Knowing that this process can extend their course from the required 14 weeks to well over a year, students may not choose to participate. However, this invitation was particularly engaging for Terry and she expressed a keen interest.

We began the project when Terry initiated contact about six weeks after the course finished, and we ended the project nearly two years later. Via email, we discussed the author guidelines for a variety of academic journals and agreed to submit a manuscript to a journal whose readership included both nurses and dietitians.

One important point of emphasis that I raised with Terry in my invitation and again at various points throughout the project was the possibility that our manuscript could be rejected. I also stressed how authors often feel a variety of emotional responses when co-authors and editors revise their work. Highlighting this aspect of the publication process was important as our first submission was rejected by the editor of the journal. Terry found that this initial rejection was one of the most difficult aspects of the project. However, this editor brought our work to an alternate journal where we were invited to reduce the word count and revise the manuscript.

\section{Cate's Story}

Cate is a Registered Psychiatric Nurse who, like Terry, was also in two of my classes. Given my own background in psychiatric mental health nursing, I found that communication with Cate was straightforward. She was an active, strong and confident participant in class discussions. She would readily ask for help when she needed it and consistently followed through on any feedback. Cate's academic writing strengthened with each assignment and her attention to detail was impressive. She instructs at a college and, like Terry, one of her personal learning goals was to develop research and publication skills.

In her closing message to me in our second course together, Cate offered to work with me on any research projects I 
was involved with. Although I did not need assistance at that time, I kept her offer in mind and several months later developed a proposal that required a paid research assistant. When funding for my proposal was approved, I contacted Cate and she accepted the position. Given the potential for exploitation of younger and vulnerable students by older faculty members simply seeking an unpaid research assistant, it was important to mentor Cate within the role of an employed research assistant. Cate's tasks included both independent and collaborative analysis of survey data, focus groups and taperecorded interviews with graduates of the MHST programme.

As we began the project, we established ground rules. With our common background in both teaching and mental health, it was not difficult to discuss our commitment to attend to and articulate emotions and concerns as they emerged. Knowing that working intensely with qualitative data gathered from graduates of Cate's own programme could be emotionally charged for her, this strategy was particularly engaging.

Just as she had done in her classes, Cate completed tasks such as coding and categorising large volumes of data promptly and thoroughly. She sought clarification and direction when she needed it and offered helpful suggestions. When offering direction to Cate, it was useful to identify that 'fitting' data into themes was a creative process that was not expected to be straightforward. Within a three-month period, we finished our qualitative analysis of the data and I presented the findings at a conference. We also co-authored a manuscript and submitted it to a refereed journal.

\section{CONCLUSION}

Adapting the Daloz model to mentoring or partnering with these graduate students towards scholarly research and writing was a positive and rewarding experience. In the area of support and establishing a trusting relationship, it was helpful to know the protégés well, to observe for cues where students themselves initiated project ideas and to establish ground rules for working together. In the area of challenge, it was useful to articulate the possibility that our manuscripts might be rejected, that the process of qualitative data analysis is seldom straightforward, and that the projects would be time consuming. In the area of vision, it was valuable to identify our goal of submitting manuscripts for publication, to discuss our motivation as educators to achieve this common goal and, on a practical level, to designate the sequence our names would be listed on manuscripts right at the beginning of the project.

In conclusion, Terry and Cate's stories begin to illustrate practical collaborative strategies for mentoring online graduate learners. Creating possibilities to involve students and partner with them in research and scholarly writing activities is both a challenge and an opportunity for faculty.

\section{References}

1 Parada C (1993) Genealogical Guide to Greek Mythology. Paul Astroms Forlag Publishing: Jonsered, Sweden.

2 Taylor L (1992) A survey of mentor relationships in academe. Journal of Professional Nursing 8: 48-55.

3 Whitley G and Oddi L (1998) Graduate student-faculty collaboration in research and publication. Western Journal of Nursing Research 20: $572-83$.

4 Whitley G, Oddi L and Terrell D (1998) Factors influencing the publishing efforts of graduate students in nursing. Journal of Nursing Education 37: 182-5.

5 Byrne MW and Keefe MR (2002) Building research competence in nursing through mentoring. Journal of Nursing Scholarship 34: 3916.

6 Paul S, Stein F, Ottenbacher K and Liu Y (2002) The role of mentoring on research productivity among occupational therapy faculty. Occupational Therapy International 9: 24-40. 
7 Braithwaite D (2002) Mentoring relationships while conducting international research. Journal of Multicultural Nursing and Health 8: 3641.

8 Owens JK and Patton JG (2003) Take a chance on nursing mentorships: enhance leadership with this win-win strategy. Nursing Education Perspectives 24: 198-204.

9 Wright TC and Howell SL (2004) Ten efficient research strategies for distance learning. Online Journal of Distance Learning Administration VII. Available at: www.westga.edu/ 2distance/ ojdla/spring71/wright71.html (accessed 16/01/ 05).

10 Northcott N (2000) Mentorship in nursing. Nursing Management 7: 30-2.

11 Fawcett DL (2002) Mentoring - what it is and how to make it work. AORN Journal 75: 950-4.

12 Morrison-Beedy D, Aronowitz T, Dyne J and Mkandawire L (2001) Mentoring students and junior faculty in faculty research: a win-win scenario. Journal of Professional Nursing 17: 291-6.

13 Davidhizar R and Dowd S (1998) Writing scholarly papers as a team. The Health Care Supervisor 16: 53-60.

14 Klein CJ and Moser-Veillon PB (1999)
Authorship: can you claim a byline? Journal of the American Dietetic Association 99: 77-9.

15 Brey R and Ogletree RJ (1999) Faculty-graduate student mentoring: implications for health education. Journal of Health Education 30: 24 9.

16 Thorpe K and Kalischuk RG (2003) A collegial mentoring model for nurse educators. Nursing Forum 38: 5-15.

17 Peters M (2000) Does constructivist epistemology have a place in nurse education? Journal of Nursing Education 39: 166-73.

18 Daloz LA (1986) Effective Teaching and Mentoring: realizing the transformational power of adult learning experiences. Jossey-Bass: San Francisco.

Correspondence to: Sherri Melrose, 136 Hawkview Manor Circle NW, Calgary, Alberta, Canada T3G 2Z8. Tel: 1-888-281-5863; email: sherrim@athabascau.ca

Sherri Melrose, PhD RN, is Assistant Professor at the Centre for Nursing and Health Studies, Athabasca University, Athabasca, Alberta, Canada.

Accepted May 2005 